
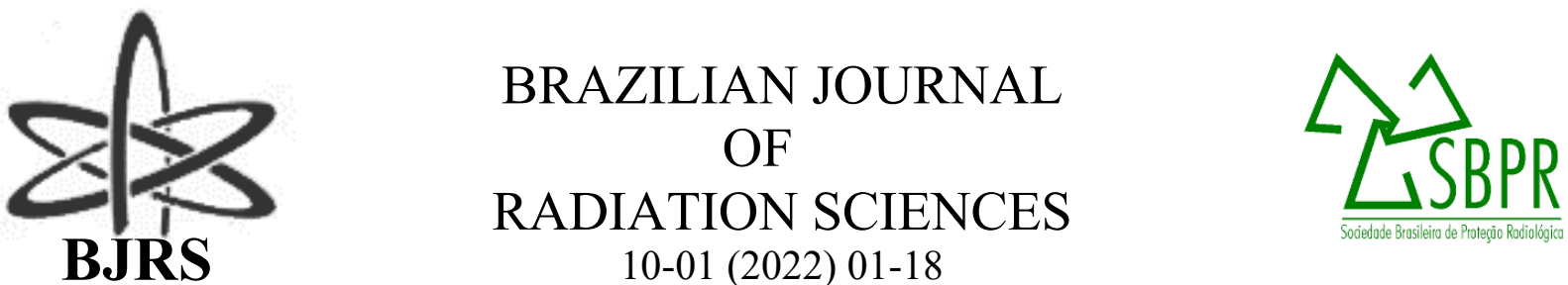

\title{
Reducing the risk for the biota by reusing a NORM residue
}

\author{
Nisti $^{a}$ M.B., Cavalcante ${ }^{a}$ F., Saueia ${ }^{a}$ C.H.R., Mazzillia B.P. \\ ${ }^{a}$ Instituto de Pesquisas Energéticas e Nucleares, IPEN/CNEN, Postal code 05508-000, São Paulo, SP, Brazil \\ mbnisti@ipen.br
}

\begin{abstract}
All biota is exposed to natural radiation, the soil being the major source of radionuclides. Phosphogypsum (PG) is classified as a NORM residue of the phosphate fertilizer industry, often used in agriculture, as a soil conditioner. This residue is stored in stacks by the phosphate industries, potentially posing environmental risks. The aim of this study is to compare the risk for the terrestrial and aquatic biota arising from the storage of PG residue in the environment with that arising from its reuse as soil amendment. For this purpose, typical Brazilian soils amended with PG and PG itself were leached with distilled water. The concentration of natural radionuclides in the soil samples were used to evaluate the risk for terrestrial and aquatic biota, using the ERICA Tool. The results for terrestrial biota exposed to soils amended with phosphogypsum showed a risk reduction of about $85 \%$, when compared to the exposure arising from phosphogypsum stacks. Considering the aquatic biota, the results showed a risk reduction of about $46 \%$ when comparing to radionuclide concentrations in leachates from phosphogypsum and from the soils amended with phosphogypsum. A new risk reduction assessment was performed to determine exclusively the contribution of the application of PG to the soil using the soil without PG, the risk reduction for terrestrial biota was of $99 \%$ and aquatic biota was a $74 \%$ reduction. Finally, it can be concluded that the addition of phosphogypsum in soils reduces the risk quotient related to the exposure of terrestrial and aquatic biota, showing that this is a safe practice.
\end{abstract}

Keywords: risk reduction; ERICA Tool; biota exposure; natural radionuclides; phosphogypsum; NORM. 


\section{INTRODUCTION}

Phosphogypsum (PG) is classified as a Naturally Occurring Radioactive Material (NORM) residue of the phosphate fertilizer industry. Some possible application of this residue is as soil conditioner, resulting in an increase of agriculture productivity, or as building material [1-3]. However, PG presents in its composition radionuclides of the natural $U$ and Th decay series, which can cause health effects. The main phosphate industries in Brazil are responsible for the annual production of 12 million tons of $\mathrm{PG}$, which is stored in open stacks beside phosphate fertilizer industry, posing environmental risks [4-6]. According to Rutherford et al. [7] and Hull and Burnett [8] the main routes of environmental risks resulting from this open storage in stacks are: atmospheric contamination, pollution of groundwater, trace elements and radionuclides, radon emanation, inhalation of dust and direct exposure to gamma radiation.

PG has been used as a soil conditioner due to the characteristics of $\mathrm{CaSO}_{4}$ to improve the physical and chemical conditions of the soil, such as: high solubility which improves the root penetration in soil, providing calcium in depth, reducing aluminum saturation, deepening the root system and favoring water absorption and nutrients, resulting in improved plant growth [9,10]. The solubility of PG in water is 150 times higher than that of calcareous rock [11].

The reuse of residues has an important role for a sustainable development and is considered as one of the 17 Sustainable Development Goals adopted by all United Nations Member States [12], that seeks solutions aiming to reduce existing waste by-products. This practice is also supported by International Atomic Energy Agency (IAEA) [13,14]. According to TECDOC 1712 of the IAEA, "Management of NORM Residues" [13], a worldwide trend towards increasing the recycling of NORM waste and its use as by-products. This conduct has been guided by sustainability considerations: concern with the depletion of non-renewable resources, increasingly restrictive environmental protection legislation, recognition that the amount of NORM waste deposited as waste must be minimized, so that its deposition can be managed.

Biota and humans are exposed to natural radiation from several sources, with different radioactivity levels and consequent exposures, which depends also on the characteristic of the region. The terrestrial exposure from the soil is associated with gamma radiation and internal exposure; aquatic exposure is also a source of internal exposure of radiation [15]. 
In the past, the levels of exposure to ionizing radiation was mainly focused on humans, considering that if human beings were adequately protected, biota and the environment were also protected. In the last decades, this statement was proven to fail and is no longer accepted [15]. Exposure and radiological risk to biota from different ecosystems can be assessed using risk models, such as the ERICA Tool [16].

The Erica Integrated Approach [16] was developed by the European Union to assess the effects of radionuclides in the environment and to support decision making. The software operates in three different Tiers and provides estimation on absorbed doses (internal and external) to reference organisms from different ecosystems and perform risk characterization based on activity concentration in the environment and in biota whole body.

The reference organisms for terrestrial biota are amphibian, bird, bird egg, detritivorous invertebrate, flying insects, gastropod, grasses and herbs, lichen and bryophytes, mammal, reptile, shrub, soil invertebrate and tree. The reference organisms for freshwater biota are: amphibian, benthic, bird, bivalve mollusk, crustacean, gastropod, insect larvae, mammal, pelagic fish, phytoplankton, vascular plant and zooplankton [16].

The aim of this study is to apply the ERICA Tool to compare the risk for the terrestrial and aquatic biota arising from the storage of PG residue in the environment with that arising from its reuse as soil and assessing the acceptability of radiation risk for the biota. This approach intends to enlarge the application of the ERICA Tool, seeking to the reutilization of NORM residues, by evaluating the reduction of the environmental impact on the biota, when compared with the deposition in stacks.

\section{MATERIALS AND METHODS}

Nisti et al. [5] determined the activity concentration of natural radionuclides $\left({ }^{238} \mathrm{U},{ }^{226} \mathrm{Ra},{ }^{210} \mathrm{~Pb}\right.$, ${ }^{210} \mathrm{Po},{ }^{232} \mathrm{Th}$ and ${ }^{228} \mathrm{Ra}$ ) in typical Brazilian soils amended with PG and PG samples. In order to study the lixiviation of radionuclides from the soils amended with PG, the authors performed a laboratory experiment in which columns containing soils, soils amended with PG and PG itself were leached with distilled water. Two typical Brazilian soil (sandy and clay) and two types of PG from different origin (named PG CUB from Cubatão stack and PG UBE from Uberaba stack, respectively) were 
used. The PG was mixed with the two soils in the proportion recommended to improve the soil fertility (D1) and 10 times the recommended quantity (D10) to be more conservative. The leachate was collected for the determination of the radionuclides concentration.

The methodology implemented for the sequential determination of ${ }^{238} \mathrm{U},{ }^{232} \mathrm{Th},{ }^{226} \mathrm{Ra},{ }^{228} \mathrm{Ra},{ }^{210} \mathrm{~Pb}$ and ${ }^{210} \mathrm{Po}$ in the leachate was based on the publication of International Atomic Energy Agency (IAEA/AQ/34) [18]. All the experimental procedure is described in Nisti et al. [5]. The experimental procedure for the sequential determination of radionuclides in the leachate is summarized in Figure 1.

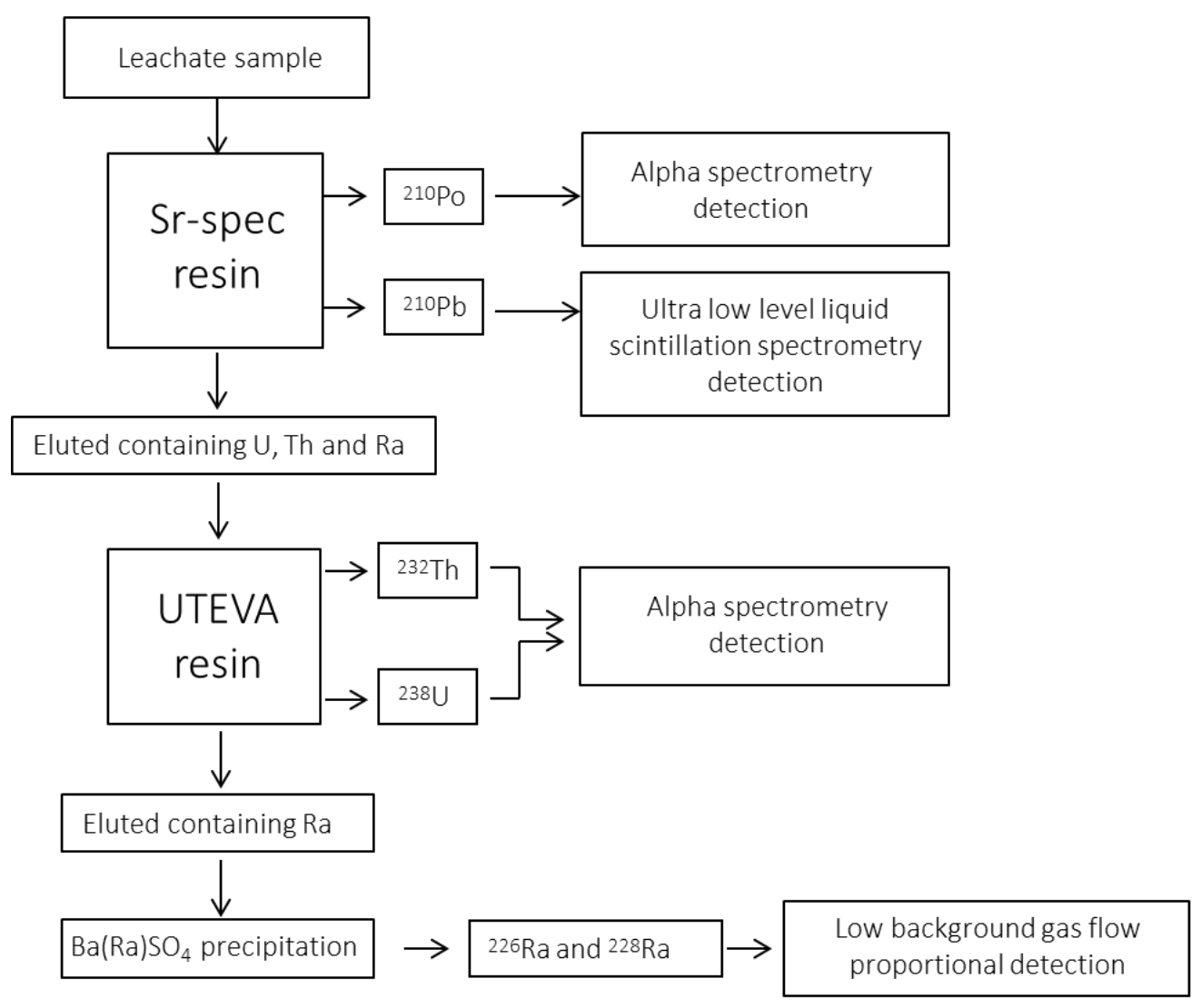

Figure 1: Diagram of sequential determination of ${ }^{210} \mathrm{Po},{ }^{210} \mathrm{~Pb},{ }^{232} \mathrm{Th},{ }^{238} \mathrm{U},{ }^{226} \mathrm{Ra}$ and ${ }^{228} \mathrm{Ra}$ in the leachate. 
Data on radionuclide concentrations on PG (CUB and UBE) and soil (clay and sandy) mixed with PG (CUB and UBE with D1 and D10) were used as input to calculate the Risk Quotient (RQ) for all terrestrial reference organisms. The assessment was run using Tier 1, once this is more conservative and simpler, only requiring average concentration activities.

Whenever the calculation of RQs presents a value equal to or higher than 1 , there is a significant probability that the activity concentration of a particular radionuclide exceeds the screening dose value $(10 \mu \mathrm{Gy}$ h-1) for the most exposed organism. The Tool suggests in this case to carry on with the assessment, using Tier 2 or Tier 3.

For the determination of the RQ the following (Eq. (1)) was used [19].

$$
R Q=\frac{C_{i}}{E M C L_{i}}
$$

Where:

$\mathrm{RQ}=$ Risk Quotient

$\mathrm{C}_{\mathrm{i}}=$ Activity Concentration for radionuclide i (Bq kg-1 for soil; Bq 1-1 for water)

$\mathrm{EMCL}_{\mathrm{i}}=$ Environmental Media Concentration Limit for radionuclide i (Bq kg-1 for soil; Bq 1-1 for water), are defined as the activity concentration in the terrestrial and in aquatic environment, with a dose-rate to the most exposed organism equal to that of the selected screening dose-rate [20].(Brown et al., 2016).

\section{RESULTS AND DISCUSSION}

The results of the activity concentration of ${ }^{238} \mathrm{U},{ }^{226} \mathrm{Ra},{ }^{210} \mathrm{~Pb},{ }^{210} \mathrm{Po},{ }^{232} \mathrm{Th}$ and ${ }^{228} \mathrm{Ra}$, in $\mathrm{PG}$ and soil + PG are presented in Table 1; and the results in the leachate are presented in Table 2. Table 1 and table 2 presents the results obtained in the referred paper (Nisti et al., 2015). 
Table 1: Mean concentration and standard deviation of ${ }^{238} \mathrm{U},{ }^{226} \mathrm{Ra},{ }^{210} \mathrm{~Pb},{ }^{210} \mathrm{Po},{ }^{232} \mathrm{Th}$ and ${ }^{228} \mathrm{Ra}$ in samples of phosphogypsum and soil + phosphogypsum $\left(\mathrm{Bq} \mathrm{kg}^{-1}\right)$ from Nisti et al. [5].

\begin{tabular}{ccccccc}
\hline Sample & U-238 & Ra-226 & Pb-210 & Po-210 & Th-232 & Ra-228 \\
\hline PG CUB & $<7$ & $294 \pm 5$ & $352 \pm 23$ & $346 \pm 7$ & $210 \pm 6$ & $228 \pm 6$ \\
PG UBE & $<7$ & $144 \pm 11$ & $149 \pm 4$ & $155 \pm 11$ & $86 \pm 8$ & $116 \pm 1$ \\
Clay soil + PG CUB_D1 & $51 \pm 2$ & $39 \pm 1$ & $51 \pm 7$ & $33 \pm 2$ & $49 \pm 1$ & $51 \pm 1$ \\
Clay soil + PG CUB_D10 & $51 \pm 2$ & $39 \pm 2$ & $54 \pm 17$ & $42 \pm 4$ & $53 \pm 1$ & $51 \pm 2$ \\
Clay soil + PG UBE_D1 & $55 \pm 4$ & $38 \pm 1$ & $54 \pm 6$ & $39 \pm 3$ & $46 \pm 5$ & $51 \pm 3$ \\
Clay soil + PG UBE_D10 & $43 \pm 2$ & $38 \pm 2$ & $47 \pm 10$ & $41 \pm 3$ & $50 \pm 3$ & $50 \pm 1$ \\
Sandy soil + PG CUB_D1 & $9 \pm 2$ & $7 \pm 1$ & $21 \pm 6$ & $16 \pm 2$ & $18 \pm 3$ & $12 \pm 3$ \\
Sandy soil + PG CUB_D10 & $12 \pm 3$ & $9 \pm 1$ & $19 \pm 2$ & $19 \pm 1$ & $19 \pm 3$ & $16 \pm 1$ \\
Sandy soil + PG UBE_D1 & $7 \pm 1$ & $7 \pm 1$ & $19 \pm 5$ & $16 \pm 1$ & $15 \pm 1$ & $13 \pm 2$ \\
Sandy soil + PG UBE_D10 & $9 \pm 1$ & $9 \pm 1$ & $21 \pm 4$ & $19 \pm 1$ & $15 \pm 2$ & $15 \pm 1$ \\
\hline
\end{tabular}

Table 2: Mean concentration and standard deviation of ${ }^{238} \mathrm{U},{ }^{226} \mathrm{Ra},{ }^{210} \mathrm{~Pb},{ }^{210} \mathrm{Po},{ }^{232} \mathrm{Th}$ and ${ }^{228} \mathrm{Ra}$ in the leachate samples $\left(\mathrm{mBq} \mathrm{L}^{-1}\right)$ from Nisti et al. [5].

\begin{tabular}{ccccccc}
\hline Sample & U-238 & Ra-226 & Pb-210 & Po-210 & Th-232 & Ra-228 \\
\hline PG CUB & $265 \pm 135$ & $81 \pm 2$ & $18 \pm 7$ & $59 \pm 6$ & $<7.5$ & $<4$ \\
PG UBE & $1487 \pm 337$ & $57 \pm 18$ & $11 \pm 4$ & $200 \pm 19$ & $<7.5$ & $<4$ \\
Clay soil + PG CUB_D1 & $<1.5$ & $38 \pm 15$ & $39 \pm 4$ & $40 \pm 21$ & $<7.5$ & $52 \pm 16$ \\
Clay soil + PG CUB_D10 & $<1.5$ & $40 \pm 22$ & $18 \pm 3$ & $41 \pm 3$ & $<7.5$ & $62 \pm 22$ \\
Clay soil + PG UBE_D1 & $<1.5$ & $26 \pm 5$ & $17 \pm 4$ & $25 \pm 3$ & $<7.5$ & $26 \pm 14$ \\
Clay soil + PG UBE_D10 & $<1.5$ & $32 \pm 7$ & $10 \pm 3$ & $37 \pm 4$ & $<7.5$ & $38 \pm 9$ \\
Sandy soil + PG CUB_D1 & $<1.5$ & $67 \pm 21$ & $30 \pm 18$ & $35 \pm 4$ & $<7.5$ & $132 \pm 21$ \\
Sandy soil + PG CUB_D10 & $<1.5$ & $54 \pm 10$ & $30 \pm 21$ & $47 \pm 4$ & $<7.5$ & $68 \pm 10$ \\
Sandy soil + PG UBE_D1 & $<1.5$ & $87 \pm 6$ & $35 \pm 6$ & $47 \pm 4$ & $<7.5$ & $161 \pm 33$ \\
Sandy soil + PG UBE_D10 & $<1.5$ & $69 \pm 12$ & $38 \pm 9$ & $37 \pm 24$ & $<7.5$ & $142 \pm 39$ \\
\hline
\end{tabular}

The concentration levels in the clay soil are four times higher than in the sandy soil; the results are in good agreement with literature values presented in the literature for Brazilian soils [21-23]. It is known that clay soils have greater ion exchange capacity and tend to retain radionuclides more 
firmly, while sandy soils, due to the macroporosity of their grains, favor faster percolation of radionuclides in water.

\subsection{Risk analysis for terrestrial biota}

Tier 1 was initially used to calculate the Risk Quotient (RQ) for terrestrial organisms, using data from Table 1 as input, the minimum detectable concentration (MDC) of ${ }^{238} \mathrm{U}$ for PG CUB and PG UBE were also considered in the calculations of the risk quotient.

The results of Risk Quotient for each radionuclide in the phosphogypsum samples are presented in Table 3.

Table 3: Risk Quotient for terrestrial biota from phosphogypsum samples

\begin{tabular}{ccc}
\hline Isotope & PG CUB & PG UBE \\
\hline $\mathrm{U}-238$ & $5.2610^{-2}$ & $5.2610^{-2}$ \\
$\mathrm{Ra}-226$ & 10.6 & 5.20 \\
$\mathrm{~Pb}-210$ & $5.6310^{-2}$ & $2.3810^{-2}$ \\
$\mathrm{Po}-210$ & 7.78 & 3.49 \\
$\mathrm{Th}-232$ & $6.7610^{-1}$ & $2.7710^{-1}$ \\
$\mathrm{Ra}-228$ & $1.7810^{-2}$ & $9.0410^{-3}$ \\
\hline
\end{tabular}

Risk quotient of ${ }^{226} \mathrm{Ra}$ and ${ }^{210} \mathrm{Po}$ calculated for the two phosphogypsum samples provide absorbed doses higher than the screening dose value $(10 \mu \mathrm{Gy} / \mathrm{h})$ for the most exposed terrestrial organisms which are, in this case, lichen and bryophytes. The exposition of the terrestrial biota arising from the PG stacks located in Cubatão is two times higher than the exposition arising from the PG stacks located in Uberaba.

The risk quotient results, obtained for each radionuclide in the mixture of clay soil mixed with the recommended dose and 10 times the recommended quantity of phosphogypsum, are presented in Table 4. 
Table 4: Risk Quotient for terrestrial biota in clay soil mixed with the recommended dose and 10 times the recommended dose

\begin{tabular}{ccccc}
\hline Isotope & $\begin{array}{c}\text { Clay soil }+ \\
\text { PG CUB (D1) }\end{array}$ & $\begin{array}{c}\text { Clay soil + } \\
\text { PG CUB (D10) }\end{array}$ & $\begin{array}{c}\text { Clay soil + } \\
\text { PG UBE (D1) }\end{array}$ & $\begin{array}{c}\text { Clay soil + } \\
\text { PG UBE (D10) }\end{array}$ \\
\hline $\mathrm{U}-238$ & $3.8410^{-1}$ & $3.8410^{-1}$ & $4.1410^{-1}$ & $3.2310^{-1}$ \\
$\mathrm{Ra}-226$ & 1.41 & 1.41 & 1.37 & 1.37 \\
$\mathrm{~Pb}-210$ & $8.1610^{-3}$ & $8.6410^{-3}$ & $8.6410^{-3}$ & $7.5210^{-3}$ \\
$\mathrm{Po}-210$ & $7.4210^{-1}$ & $9.4510^{-1}$ & $8.7810^{-1}$ & $9.2210^{-1}$ \\
$\mathrm{Th}-232$ & $1.5810^{-1}$ & $1.7110^{-1}$ & $1.4810^{-1}$ & $1.6110^{-1}$ \\
$\mathrm{Ra}-228$ & $3.9710^{-3}$ & $3.9710^{-3}$ & $3.9710^{-3}$ & $3.9010^{-3}$ \\
\hline
\end{tabular}

The risk quotient of ${ }^{226} \mathrm{Ra}$ calculated in clay soil mixed with the recommended dose and 10 times the recommended dose of PG provides absorbed doses to the terrestrial organism higher than the screening dose value for the most exposed organisms (lichen and bryophytes). Furthermore, no difference was observed in the risk quotient when the amount of PG added to the clay soil increased by 10 times, showing that the exposition to the terrestrial biota is mainly due to the radionuclides originally present in the soil.

Table 5 presents the results obtained for the risk quotient of each radionuclide in the mixture of sandy soil with the recommended dose and 10 times the recommended dose of phosphogypsum, using the data from Table 1.

Table 5: Risk Quotient for terrestrial biota in sandy soil mixed with the recommended dose and 10 times the recommended dose

\begin{tabular}{ccccc}
\hline Isotope & $\begin{array}{c}\text { Sandy soil }+ \\
\text { PG CUB (D1) }\end{array}$ & $\begin{array}{c}\text { Sandy soil + } \\
\text { PG CUB (D10) }\end{array}$ & $\begin{array}{c}\text { Sandy soil + } \\
\text { PG UBE (D1) }\end{array}$ & $\begin{array}{c}\text { Sandy soil + } \\
\text { PG UBE (D10) }\end{array}$ \\
\hline $\mathrm{U}-238$ & $6.7710^{-2}$ & $9.0210^{-2}$ & $5.2610^{-2}$ & $6.7710^{-2}$ \\
$\mathrm{Ra}-226$ & $2.5310^{-1}$ & $3.2510^{-1}$ & $2.5310^{-1}$ & $3.2510^{-1}$ \\
$\mathrm{~Pb}-210$ & $3.3610^{-3}$ & $3.0410^{-3}$ & $3.0410^{-3}$ & $3.3610^{-3}$ \\
$\mathrm{Po}-210$ & $3.6010^{-1}$ & $4.2810^{-1}$ & $3.6010^{-1}$ & $4.2810^{-1}$ \\
$\mathrm{Th}-232$ & $5.8010^{-2}$ & $6.1210^{-2}$ & $4.8310^{-2}$ & $4.8310^{-2}$ \\
$\mathrm{Ra}-228$ & $9.3510^{-4}$ & $1.2510^{-3}$ & $1.0110^{-3}$ & $1.1710^{-3}$ \\
\hline
\end{tabular}


The risk quotient measured in sandy soil mixed with both phosphogypsum in the recommended dose and 10 times the recommended dose was below the screening dose value. Therefore, for the sandy soil, the use of PG as soil amendment does not imply in additional risk for the terrestrial biota.

\subsection{Risk analysis for aquatic biota}

Tier 1 was initially used to calculate the risk quotients for aquatic organisms (using reference organisms for freshwater biota), using data from Table 2 as input, the MDC $\left({ }^{238} \mathrm{U},{ }^{232} \mathrm{Th}\right.$ and $\left.{ }^{228} \mathrm{Ra}\right)$ were also considered in the calculations of the Risk Quotient.

The results of the Risk Quotient for each radionuclide in the phosphogypsum leachate samples are presented in Table 6.

Table 6: Risk Quotient for aquatic biota in the leachate samples of PG.

\begin{tabular}{ccc}
\hline Isotope & PG CUB & PG UBE \\
\hline $\mathrm{U}-238$ & $8.9610^{-1}$ & 5.03 \\
$\mathrm{Ra}-226$ & 89.1 & 62.7 \\
$\mathrm{~Pb}-210$ & $1.6110^{-2}$ & $9.8210^{-3}$ \\
$\mathrm{Po}-210$ & 40.7 & 138 \\
$\mathrm{Th}-232$ & 6.67 & 6.67 \\
$\mathrm{Ra}-228$ & $1.6010^{-2}$ & $1.6010^{-2}$ \\
\hline
\end{tabular}

Risk quotient of ${ }^{226} \mathrm{Ra},{ }^{210} \mathrm{Po}$ and ${ }^{232} \mathrm{Th}$ calculated in phosphogypsum leachate samples provided absorbed doses higher than the screening dose; the limiting reference organism for ${ }^{226} \mathrm{Ra}$ and ${ }^{210} \mathrm{Po}$ being insect larvae and for ${ }^{232} \mathrm{Th}$ being vascular plant.

The risk quotient results obtained for each radionuclide in the leachate of the clay soil mixed with phosphogypsum are presented in Table 7. 
Table 7: Risk Quotient for aquatic biota in leachate samples of clay soil mixed with PG

\begin{tabular}{ccccc}
\hline Isotope & $\begin{array}{c}\text { Sandy soil + } \\
\text { PG CUB (D1) }\end{array}$ & $\begin{array}{c}\text { Sandy soil + } \\
\text { PG CUB (D10) }\end{array}$ & $\begin{array}{c}\text { Sandy soil + } \\
\text { PG UBE (D1) }\end{array}$ & $\begin{array}{c}\text { Sandy soil + } \\
\text { PG UBE (D10) }\end{array}$ \\
\hline $\mathrm{U}-238$ & $5.0710^{-3}$ & $5.0710^{-3}$ & $5.0710^{-3}$ & $5.0710^{-3}$ \\
$\mathrm{Ra}-226$ & 41.8 & 44.0 & 28.6 & 35.2 \\
$\mathrm{~Pb}-210$ & $3.4810^{-2}$ & $1.6110^{-2}$ & $1.5210^{-2}$ & $8.9310^{-3}$ \\
$\mathrm{Po}-210$ & 27.6 & 28.3 & 17.2 & 25.5 \\
$\mathrm{Th}-232$ & 6.67 & 6.67 & 6.67 & 6.67 \\
$\mathrm{Ra}-228$ & $2.0810^{-1}$ & $2.4810^{-1}$ & $1.0410^{-1}$ & $1.5210^{-1}$ \\
\hline
\end{tabular}

Risk quotients of ${ }^{226} \mathrm{Ra},{ }^{210} \mathrm{Po}$ and ${ }^{232} \mathrm{Th}$ calculated in the leachate samples of mixtures of clay soil plus PG from two provenances at different doses provided absorbed doses higher than the screening dose value; the limiting reference organism being insect larvae for ${ }^{226} \mathrm{Ra}$ and ${ }^{210} \mathrm{Po}$ and vascular plant for ${ }^{232} \mathrm{Th}$. No significant differences were observed in the exposition of the aquatic biota, for the leachate of clay soil when the amount of PG added increased by 10 times, showing that the exposition to the aquatic biota is mainly due to the radionuclides originally present in the clay soil.

The risk quotient results obtained for each radionuclide in the leachate of the sand soil mixed with phosphogypsum are presented in Table 8 .

Table 8: Risk Quotient for aquatic biota in leachate samples of sand soil mixed with PG

\begin{tabular}{ccccc}
\hline Isotope & $\begin{array}{c}\text { Sandy soil }+ \\
\text { PG CUB (D1) }\end{array}$ & $\begin{array}{c}\text { Sandy soil + } \\
\text { PG CUB (D10) }\end{array}$ & $\begin{array}{c}\text { Sandy soil + } \\
\text { PG UBE (D1) }\end{array}$ & $\begin{array}{c}\text { Sandy soil + } \\
\text { PG UBE (D10) }\end{array}$ \\
\hline $\mathrm{U}-238$ & $5.0710^{-3}$ & $5.0710^{-3}$ & $5.0710^{-3}$ & $5.0710^{-3}$ \\
$\mathrm{Ra}-226$ & 73.7 & 59.4 & 95.7 & 75.9 \\
$\mathrm{~Pb}-210$ & $2.6810^{-2}$ & $2.6810^{-2}$ & $3.1310^{-2}$ & $3.3910^{-2}$ \\
$\mathrm{Po}-210$ & 24.2 & 32.4 & 32.4 & 25.5 \\
$\mathrm{Th}-232$ & 6.67 & 6.67 & 6.67 & 6.67 \\
$\mathrm{Ra}-228$ & $5.2810^{-1}$ & $2.7210^{-1}$ & $6.4410^{-1}$ & $5.6810^{-1}$ \\
\hline
\end{tabular}

Risk quotients of ${ }^{226} \mathrm{Ra},{ }^{210} \mathrm{Po}$ and ${ }^{232} \mathrm{Th}$ calculated in the leachate samples of mixtures of sand soil plus PG from two provenances at different doses provided absorbed doses higher than the 
screening dose value; the limiting reference organism being insect larvae for ${ }^{226} \mathrm{Ra}$ and ${ }^{210} \mathrm{Po}$ and vascular plant for ${ }^{232} \mathrm{Th}$. No significant differences were observed in the exposition of the aquatic biota, for the leachate of sand soil when the amount of PG added increased by 10 times, showing that the exposition to the aquatic biota is mainly due to the radionuclides originally present in the sand soil.

\subsection{Summation of risk for terrestrial and aquatic biota}

The results of the summation of the risk quotient for the terrestrial biota arising from the PG and the soil mixed with PG, and for the aquatic biota arising from the corresponding leachates are presented in Table 9.

Table 9: Risk coefficient estimate for terrestrial and aquatic biota

\begin{tabular}{ccc|cc}
\hline \multirow{2}{*}{ Sample } & \multicolumn{2}{c|}{$\begin{array}{c}\text { Risk Quotient } \\
\text { Terrestrial biota }\end{array}$} & $\begin{array}{c}\text { Risk Quotient } \\
\text { Aquatic biota }\end{array}$ \\
\hline PG CUB & \multicolumn{2}{c|}{19.2} & \multicolumn{2}{c}{$1.3710^{2}$} \\
PG UBE & \multicolumn{2}{c|}{9.05} & \multicolumn{2}{c}{$2.1210^{2}$} \\
\cline { 2 - 5 } & \multicolumn{2}{c|}{ D1 } & D10 & D10 \\
\hline Clay soil + PG CUB & 2.70 & 2.92 & 76.3 & 79.2 \\
Clay soil + PG UBE & 2.82 & 2.79 & 52.6 & 67.6 \\
Sandy soil + PG CUB & $7.4310^{-1}$ & $9.0810^{-1}$ & $1.0510^{2}$ & 98.8 \\
Sandy soil + PG UBE & $7.1810^{-1}$ & $8.7310^{-1}$ & $1.3510^{2}$ & $1.0910^{2}$ \\
\hline
\end{tabular}

The exposition of the terrestrial biota arising from the PG stacks located in Cubatão is two times higher than the exposition arising from the PG stacks located in Uberaba; whereas the exposition of the aquatic biota was higher for the PG leachate from Uberaba.

The total risk quotient for the terrestrial biota measured in sandy soil mixed with phosphogypsum in the recommended dose and 10 times the recommended dose was below the screening dose value. Therefore, for the sandy soil, the use of PG as soil amendment does not imply in additional risk for the terrestrial biota. The exposure of the aquatic biota arising from the leachates of the sandy soil with PG provided always absorbed doses higher than the screening dose value. 
The total risk quotient for the terrestrial and aquatic biota measured in clay soil mixed with phosphogypsum in the recommended dose and 10 times the recommended dose provided absorbed doses higher than the screening dose value for the most exposed organism.

The radionuclides are more available in the sandy soil leachate, a explanation to this behavior is the lower $\mathrm{pH}$ and lower Cation Exchange Capacity (CEC) of the sandy soil compared to the clay soil.

The total risk obtained for the terrestrial and aquatic biota considering the use of the recommended dose (D1) and 10 times the recommended dose (D10) of PG did not change significantly, demonstrating that the addition of phosphogypsum in the two types of soil did not contribute to an increase in the exposure of the biota, reinforcing the practice of reusing PG as soil conditioner.

The risk reduction for the terrestrial biota was obtained by comparing the total risk obtained from the PGs with those obtained from the mixtures of soil + PG. For the aquatic biota, the risk reduction was obtained by comparing the total risk obtained from the PG leachates with those obtained from the leachates of the mixtures of soil + PG. The results are presented in Table 10 .

Table 10: Risk reduction for terrestrial and aquatic biota (\%)

\begin{tabular}{ccc|cc}
\hline & Terrestrial biota & \multicolumn{2}{c}{ Aquatic biota } \\
Sample & D1 & D10 & D1 & D10 \\
\hline Clay soil + PG CUB & 86 & 85 & 44 & 42 \\
Clay soil + PG UBE & 69 & 69 & 75 & 68 \\
Sandy soil + PG CUB & 96 & 95 & 23 & 28 \\
Sandy soil + PG UBE & 92 & 90 & 36 & 49 \\
\hline Mean & 86 & 85 & 45 & 47 \\
\hline
\end{tabular}

The results for terrestrial biota exposed to soils amended with phosphogypsum showed a risk reduction of about $85 \%$, when compared with the exposure arising from phosphogypsum in stacks. Considering the aquatic biota, the results showed a risk reduction of about $46 \%$ when comparing the radionuclides concentration in the leachates from phosphogypsum and from the soils amended with phosphogypsum.

The results of risk reduction for terrestrial and aquatic biota were similar for both scenario (D1 and D10), even in quantities that exceeded ten times the amount of PG of the recommended dose. 
The soil (clay and sandy) without amended with PG and leachate in the soil (clay and sandy) without amended with PG were analyzed, the results of the activity concentration of ${ }^{238} \mathrm{U},{ }^{226} \mathrm{Ra},{ }^{210} \mathrm{~Pb}$, ${ }^{210} \mathrm{Po},{ }^{232} \mathrm{Th}$ and ${ }^{228} \mathrm{Ra}$ are presented in Table 11 [5].

Table 11: Mean concentration and standard deviation of ${ }^{238} \mathrm{U},{ }^{226} \mathrm{Ra},{ }^{210} \mathrm{~Pb},{ }^{210} \mathrm{Po},{ }^{232} \mathrm{Th}$ and ${ }^{228} \mathrm{Ra}$ in samples of soil without amended with PG $\left(\mathrm{Bq} \mathrm{kg}^{-1}\right)$ and in the leachate samples of soil without amended with PG $\left(\mathrm{mBq} \mathrm{L}^{-1}\right)$ from Nisti et al. [5].

\begin{tabular}{ccccccc}
\hline Sample & U-238 & Ra-226 & Pb-210 & Po-210 & Th-232 & Ra-228 \\
\hline \multirow{7}{*}{ Clay soil } & $40 \pm 2$ & $38 \pm 1$ & $46 \pm 8$ & $38 \pm 2$ & $52 \pm 1$ & $51 \pm 2$ \\
Sandy soil & $11 \pm 1$ & $6 \pm 1$ & $13 \pm 2$ & $14 \pm 1$ & $14 \pm 2$ & $12 \pm 1$ \\
\hline \multirow{2}{*}{ Leachate clay soil } & $<1.5$ & $21 \pm 13$ & $15 \pm 7$ & $35 \pm 13$ & $<7.5$ & $29 \pm 12$ \\
Leachate sand soil & $<1.5$ & $17 \pm 11$ & $14 \pm 8$ & $20 \pm 3$ & $<7.5$ & $20 \pm 14$ \\
\hline
\end{tabular}

The results of the summation of the risk quotient for the terrestrial biota arising from the soil (clay and sandy) without amended with PG, and for the aquatic biota arising from the corresponding leachates in soil (clay and sandy) without PG are presented in Table 12.

Table 12: Summation of risk quotient for terrestrial and aquatic biota (soil and leachate without amended with PG)

\begin{tabular}{cc|c}
\hline Sample & $\begin{array}{c}\sum \text { Risk Quotient } \\
\text { Terrestrial biota }\end{array}$ & $\begin{array}{c}\sum \text { Risk Quotient } \\
\text { Aquatic biota }\end{array}$ \\
\hline Clay soil & 2.71 & 54.1 \\
Sandy soil & $6.6210^{-1}$ & 39.3 \\
\hline
\end{tabular}

A new risk reduction assessment was performed to determine exclusively the contribution of the application of PG to the soil was determined using the soil without PG.

The risk reduction for terrestrial biota in soil + PG decreasing the contribution of total risk in soil without PG was of $99 \%$, showing that the contribution of PG in the soil was negligible, not result in unacceptable radiation risks to terrestrial biota. 
For aquatic biota considering the leachate samples in the soil amended with PG discounting the contribution of soil without PG was a 74\% reduction (calculated by discounting the soil risk coefficient to the risk coefficient obtained in the soil with PG, thus considering only the contribution of PG in the soil). Risk quotient in the aquatic environment were greater than 1, but the methodology used did not considered the dilution factor in the aquatic environment. The risk quotient for aquatic biota determines the dilution factor necessary for the receiving aquatic environment to result in the risk quotient less than 1 for aquatic biota.

The information on the background level of the natural radionuclides is important for to compare with of NORM residue site to determine if the incremental value is likely to be of concern [24].

\section{CONCLUSIONS}

This work proposed to apply the ERICA Tool to compare the risk for the terrestrial and aquatic biota arising from the storage of PG residue in the environment with that arising from its reuse as soil amendment. This approach intended to enlarge the application of the ERICA Tool, reinforcing practices of reutilization of NORM residues that reduces the environmental impact on the biota, when compared with the practice of deposition in stacks. Furthermore, the ERICA Tool can be useful in assisting environmental radiological monitoring program for decision-making.

The results for terrestrial biota exposed to soils amended with phosphogypsum showed a risk reduction of about $85 \%$, when compared with the exposure arising from phosphogypsum in stacks. Considering the aquatic biota, the results showed a risk reduction of about $46 \%$ when comparing the radionuclides concentration in the leachates from phosphogypsum and from the soils amended with phosphogypsum.

A new risk reduction assessment was performed to determine exclusively the contribution of the application of PG to the soil was determined using the soil without PG, the risk reduction for terrestrial biota was of $99 \%$ and aquatic biota was a $74 \%$ reduction. A recommendation of this paper is to use the risk quotient of the aquatic biota to determine the dilution factor necessary to not exceed the value of 1 . 
The results of risk reduction for terrestrial and aquatic biota were similar for both scenario (D1 and D10), even in quantities that exceeded ten times the amount of PG of the recommended dose.

Finally, it can be concluded that the addition of phosphogypsum in soils reduces the risk related to the exposure of terrestrial and aquatic biota, showing that this is a safe practice from the radiological point of view. Furthermore, this practice reduces the amount of phosphogypsum disposed in stacks and consequent environmental impact.

This paper contributed to:

- Add value to phosphogypsum, following the world trend of increasing the reuse of NORM residue and preserving natural resources for a sustainable development;

- Reinforce the reuse of phosphogypsum as a soil conditioner, reducing the exposition of the terrestrial and aquatic biota resulting from this practice in comparison with the exposition from the phosphogypsum stacks;

- Reduce the amount of PG disposed in stacks and consequent environmental impact;

- Comply with the environmental protection legislation, reducing the radiological impact in the terrestrial and aquatic biota;

- Avoid depletion of non-renewable resources, considering the principles of sustainable development. 


\section{REFERENCES}

[1] VAN RAIJI, B. Gesso Agrícola na Melhoria do Ambiente Radicular no Subsolo. first ed. ANDA, São Paulo. 1988.

[2] VITTI, G.C., LUZ, P.H.C., MALAVOLTA, E., DIAS, A.S., SERRANO, C.G.E. Uso do Gesso em Sistemas de Produção Agrícola, first ed. GAPE, Piracicaba, São Paulo, Brazil. 2008.

[3] CAMPOS, M.P., COSTA, L.J.P., NISTI, M.B., MAZZILLI, B.P. Phosphogypsum recycling in the building materials industry: assessment of the radon exhalation rate. J Environ Radioact, v. 172, p. 232-236, 2017.

[4] MAZZILLI, B.P., PALMIRO, V., SAUEIA, C.R, NISTI, M.B. Radiochemical characterization of Brazilian phosphogypsum. J Environ Radioact, v. 49, p. 113-122, 2000. https://doi.org/10.1016/S0265-931X(99)00097-1.

[5] NISTI, M.B., SAUEIA, C.R., MALHEIRO, L.H., GROPPO, G.H., MAZZILLI, B.P. Lixiviation of natural radionuclides and heavy metals in tropical soils amended with phosphogypsum. $\mathbf{J}$ Environ Radioact, v. 144, p. 120-126, 2015. https://doi.org/10.1016/j.jenvrad.2015.03.013.

[6] MAZZILLI B.P., CAMPOS M.P., NISTI M.B., SAUEIA C.H.R., MADUAR M.F. Radiological implications of using phosphogypsum as building material: a case study of Brazil. Braz J Radiat Sci, v. 08 (01), p. 01-29, 2020.

[7] RUTHERFORD, P.M., DUDAS, M.J.; SAMEK, R.A. Environmental Impacts of Phosphogypsum. The Science of The Total Environment. v.149, p.1-38. 1994.

[8] HULL, C.D.; BURNETT, W.C. Radiochemistry of Florida phosphogypsum. J Environ Radioac, v. $32(3)$, p. 213-238, 1996.

[9] PAPAStefanou, C., StOUlos, S., IOANNIDOU, A., MANOlOPOUlOU, M. The application of phosphogypsum in agriculture and the radiological impact. J Environ Radioact, v. 89 (2), p. 188-198, 2006.

[10] OLIVEIRA, K.A.P. Aplicação do fosfogesso na agricultura do cerrado e suas implicações radiológicas. Master Thesis - Centro de Desenvolvimento da Tecnologia Nuclear CDTN/CNEN/MG, Minas Gerais. 128. 2008. 
[11] VITTI, G.C. Acidez do solo, calagem e gessagem. In: Curso de atualização em fertilidade do solo, Fundação Cargill. Ilha Solteira, São Paulo, Brazil. 1987.

[12] UN-SDGs - United Nations. The 17 Sustainable Development Goals (SDGs). 2015. Accessible at: https://sustainabledevelopment.un.org/.

[13] IAEA - International Atomic Energy Agency. Management of NORM Residues. TECDOC 1712. IAEA, 2013 Vienna.

[14] IAEA - International Atomic Energy Agency. Radiation Protection and Safety of Radiation Sources: International Basic Safety Standards - Safety Standards Series No. GSR Part 3. IAEA, 2014, Vienna.

[15] UNSCEAR - United Nations Scientific Committee on the Effects of Atomic Radiation. Sources, Effects and Risks of Ionization Radiation; Report to the General Assembly, with Annexes. UNSCEAR, New York, 2000.

[16] Brown, J. E., Alfonso, B., AVIlA, R., BERESFORD, N. A., COPPleStOnE, D., PROHL, G., ULANOVSKY, A. The ERICA Tool. J Environ Radioact, v. 99 (9), p. 1371-1383, 2008. https://doi.org/10.1016/j.jenvrad.2008.01.008.

[17] CUTSHALL, N.H., LARSEN, I.L., OLSEN, C.R. Direct analysis of ${ }^{210} \mathrm{~Pb}$ in sediment samples: Self-absorption corrections. Nucl Instrum Methods Phys Res, v. 206, p. 309-312, 1983. https://doi.org/10.1016/0167-5087(83)91273-5.

[18] IAEA - International Atomic Energy Agency. A Procedure for the Sequential Determination of Radionuclides in Phosphogypsum, Analytical Quality in Nuclear Applications Series No. 34, IAEA, 2014, Vienna.

[19] PRLIC, I., MOSTECAK, A., MIHIC, M. S., VEINOVIC, Ž., PAVELIC, L. Radiological risk assessment: an overview of the ERICA Integrated Approach and the ERICA Tool use. Arh Hig Rada Toksikol. v. 68, p. 298-307. 2017. https://doi.org/10.1515/aiht-2017-68-3020.

[20] BRoWn, J.E., Alfonso, B., AVILA, R., BERESFORD, N.A., COPPleStONE, D., HOSSEINI, A. A new version of the ERICA tool to facilitate impact assessments of radioactivity on wild plants and animals. J Environ Radioact, v. 153, p. 141-148, 2016. https:// doi.org/10.1016/j.jenvrad.2015.12.011. 
[21] Peres, A.C., 2007. Modelo para o estabelecimento de valores orientadores para elementos radioativos no solo. Thesis Dissertation - Instituto de Pesquisas Energéticas e Nucleares IPEN/CNEN/SP, São Paulo, Brazil.

[22] MAZZILli, B.P., SAUEIA, C.H.R., JACOMINO, V.M.F., MELLO, J.W.V. Natural radionuclides and metals intake into soya, corn and lettuce grown on soil amended with phosphogypsum. Int J Environ Anal Chem, v. 92, p. 1574-1586, 2012. https://doi.org/10.1080/03067319.2010.549339.

[23] RUBY, E.C; FIGUEIREDO, A.M.G.; MODESTO, R.P.; LEMOS, M.M.G. Tório e urânio em solos agrícolas do Estado de São Paulo. In: XIV Congresso Brasileiro de Geoquímica, 13-18 de outubro, Diamantina, MG. 2013

[24] ĆUJIC, M., DRAGOVIC, S. Assessment of dose rate to terrestrial biota in the area around coal fired power plant applying ERICA tool and RESRAD BIOTA code. J Environ Radioac, v. 188, p. 108-114, 2018. 